\title{
PENGEMBANGAN SISTEM MONITORING PENCEMARAN UDARA BERBASIS PROTOKOL ZIGBEE DENGAN SENSOR CO
}

\author{
Ramdan Satra ${ }^{1}$, Abdul Rachman ${ }^{2}$ \\ 11ramdan@umi.ac.id, 2emanrstc@yahoo.co.id \\ 1,2Fakultas IImu Komputer Universitas Muslim Indonesia
}

\begin{abstract}
Absrak
Pencemaran udara merupakan suatu masalah yang berdampak buruk bagi kehidupan makhluk hidup. Udara yang tercemar akan menimbulkan berbagai macam penyakit, sehingga perlu dilakukan pengamatan tingkat pencemaran udara pada lingkungan masyarakat. Penelitian ini telah mengembangkan sistem monitoring tingkat pencemaran udara menggunakan protokol zigbee dengan mengunakan sensor gas CO (Karbon Monoksida). Penelitian ini menggunakan protocol zigbee sebagai media transmisi tanpa kabel, kemudian menggunakan arduino with socket xbee dan sensor gas MQ-9 sebagai stasiun node. Hasil penelitian ini adalah prototype sistem monitoring tingkat pencemaran udara gas karbon monoksida berbasis protokol zigbee dan telah berhasil mengirimkan hasil pengambilan data pencemaran udara dari client node sensor gas $\mathrm{CO}$ ke server raspberry pi.
\end{abstract}

Kata kunci: monitoring, pencemaran udara, protokol zigbee, arduino, sensor gas CO.

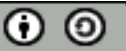

EY ILKOM Jurnal Ilmiah work is licensed under a CCA-SA 4.0 International License.

\section{Pendahuluan}

Pencemaran udara merupakan suatu masalah yang berdampak buruk bagi kehidupan makhluk hidup. Udara yang tercemar akan menimbulkan berbagai macam penyakit, sehingga perlu dilakukan pengamatan tingkat pencemaran udara pada lingkungan masyarakat. Dampak perubahan kualitas udara akan menyebabkan timbulnya beberapa dampak lanjutan, baik terhadap kesehatan manusia dan makhluk hidup lainnya, aspek estetika udara, keutuhan bangunan, dan lainnya. Dampak terhadap kesehatan manusia yang banyak terjadi adalah iritasi mata dan gangguan infeksi saluran pernafasan atas (ISPA), seperti hidung berair, radang batang tenggorokan, dan bronkitis. Partikel berukuran kecil dapat masuk sampai ke paru-paru dan kemudian menyebar melalui sistem peredaran darah ke seluruh tubuh. Gas CO (karbon monoksida), jika bercampur dengan hemoglobin, akan mengganggu transportasi oksigen. Partikel timbal akan mengganggu pembentukan sel darah merah [1].

Kepedulian pemerintah terkait penanganan pencemaran udara yaitu dengan membuat keputusan No KEP- 107/KABAPEDAL/11/1997 menetapkan aturan tentang pedoman teknis perhitungan dan pelaporan serta informasi indeks standar pencemar udara (ISPU) [2]. ISPU merupakan laporan kualitas udara yang menerangkan seberapa tercemar dan bersihnya udara pada lingkungan masyarakat [3]. Pemerintah menetapkan parameter ISPU dengan lima jenis pencemaran udara yaitu $\mathrm{CO}, \mathrm{SO} 2, \mathrm{NO} 2$, Ozon permukaan (O3), dan partikel debu (PM-10) [2]. ISPU dikategorikan kedalam 5 tingkatan pengukuran yaitu 1) kategori baik rentang nilai pengukuran $0-50,2)$ kategori sedang $(51-100), 3)$ kategori tidak sehat $(101-199), 4)$ kategori sangat tidak sehat $(200-299), 5)$ kategori berbahaya $(300-500)$ [2].

Stasiun pengamatan ISPU sangat diperlukan dalam lingkungan masyarakat Indonesia, upaya pemeriah adalah telah membuat stasiun ISPU pada setiap propinsi di Indonesia. Stasiun ISPU yang ada di Indonesia menggunakan perangkat intrumentasi yang didatanggkan dari luar negeri, sehinngga memerlukan biaya mahal untuk pengadaannya [3]. Pengembangan stasiun ISPU telah dilakukan oleh Aziz yaitu membuat sebuah sistem informasi pengukuran nilai ISPU yang terdiri tiga bagian utama yaitu 1) stasiun akuisisi sensor gas pencemar udara, 2) server pengumpul dan penyimpan data, 3) tampilan antar muka untuk mengakses data. Setiap stasiun memiliki lima buah sensor untuk membaca gas $\mathrm{CO}, \mathrm{SO} 2, \mathrm{NO} 2$, Ozon permukaan (O3), dan partikel debu (PM-10). Media komunikasi data pada menggunakan jaringan wireless selanjutnya ditampilkan secara waktu nyata (real time) dan secara tidak waktu nyata oleh aplikasi desktop dan aplikasi web [3]. Namun pada penelitian Aziz hanya diterapkan pada lingkungan Kampus IPB dan server akuisisi data menggunakan PC (Personal Computer), hal ini menjadi alasan peneliti dalam melakukan penelitian pengataman tingkat pencemaran udara pada lingkungan UMI terkhusus Fakultas IImu komputer menggunakan server raspberry pi.

\section{Landasan Teori}

\subsection{ISPU}


Penjelasan Bapedal 1998: “... keputusan Menteri Negara Lingkungan Hidup tentang Indeks Standar Pencemar Udara (ISPU) nomor KEP-45/MENLH/10/1997, ISPU didefinisikan sebagai angka yang tidak mempunyai satuan yang menggambarkan kondisi kualitas udara ambien di lokasi dan waktu tertentu yang didasarkan kepada dampak terhadap kesehatan manusia, nilai estetika dan makhluk hidup lainnya ....".

Tabel 1 Kategori, rentang, dan indikator warna ISPU

\begin{tabular}{|c|c|c|c|}
\hline Kategori & Rentang & Indikator warna & Penjelasan \\
\hline Baik & $0-50$ & Hijau & $\begin{array}{l}\text { Tingkat kualitas udara yang tidak } \\
\text { memberikan efek bagi kesehatan manusia } \\
\text { atau hewan dan tidak berpengaruh pada } \\
\text { tumbuhan, bangunan ataupun nilai estetika }\end{array}$ \\
\hline Sedang & $51-100$ & Biru & $\begin{array}{l}\text { Tingkat kualitas udara yang tidak } \\
\text { memberikan efek bagi kesehatan manusia } \\
\text { atau hewan tetapi } \\
\text { berpengaruh pada tumbuhan yang sensitif, } \\
\text { dan nilai estetika tumbuhan, bangunan } \\
\text { ataupun nilai estetika }\end{array}$ \\
\hline Tidak Sehat & $101-199$ & Kuning & $\begin{array}{l}\text { Tingkat kualitas udara yang bersifat } \\
\text { merugikan pada manusia ataupun } \\
\text { kelompok hewan yang sensitif atau bisa } \\
\text { menimbulkan kerusakan pada } \\
\text { tumbuhan ataupun nilai estetika }\end{array}$ \\
\hline $\begin{array}{l}\text { Sangat tidak } \\
\text { sehat }\end{array}$ & 200-299 & Merah & $\begin{array}{l}\text { Tingkat kualitas udara yang dapat } \\
\text { merugikan kesehatan pada sejumlah } \\
\text { segmen populasi yang terpapar }\end{array}$ \\
\hline Berbahaya & $>299$ & Hitam & $\begin{array}{l}\text { Tingkat kualitas udara berbahaya yang } \\
\text { secara umum dapat merugikan kesehatan } \\
\text { vang serius pada populasi }\end{array}$ \\
\hline
\end{tabular}

Sumber:

Keputusan Kepala Badan Pengendalian Dampak Lingkungan Tentang Pedoman Teknis Perhitungan dan Pelaporan Serta Informasi Indeks Standar Pencemar Udara (ISPU) nomor: KEP. 107/KABAPEDAL/11/1997 pasal 8.

Kandungan parameter pencemaran lingkungan yang melewati ketentuan batas ambang, akan berdampak pada lingkungan masyarakat [2].

Tabel 2 Memperlihatkan pengaruh ISPU untuk setiap parameter pencemar

\begin{tabular}{|c|c|c|c|c|c|}
\hline Kategori & $\begin{array}{c}\text { Karbon } \\
\text { Monoksida } \\
\text { (CO) }\end{array}$ & $\begin{array}{l}\text { Nitrogen } \\
\text { (NO2) }\end{array}$ & Ozon (03) & $\begin{array}{l}\text { Sulfur Dioksida } \\
\text { (SO2) }\end{array}$ & $\begin{array}{c}\text { Partikel } \\
\text { Debu (PM- } \\
10)\end{array}$ \\
\hline Baik & Tidak ada efek & Sedikit berbau & $\begin{array}{l}\text { Luka pada } \\
\text { beberapa spesies } \\
\text { tumbuhan akibat } \\
\text { kombinasi dengan } \\
\text { SO2 (Selama } 4 \\
\text { Jam) }\end{array}$ & $\begin{array}{l}\text { Luka pada } \\
\text { beberapa } \\
\text { spesies } \\
\text { tumbuhan } \\
\text { akibat } \\
\text { kombinasi } \\
\text { dengan O3 } \\
\text { (Selama } 4 \text { Jam) }\end{array}$ & $\begin{array}{l}\text { Tidak ada } \\
\text { efek }\end{array}$ \\
\hline Sedang & $\begin{array}{l}\text { Perubahan kimia } \\
\text { darah tapi tidak } \\
\text { Terdeteksi }\end{array}$ & Berbau & $\begin{array}{l}\text { Luka pada } \\
\text { babarapa } \\
\text { Spesies } \\
\text { tumbuhan }\end{array}$ & $\begin{array}{l}\text { Luka } \\
\text { padaBeberapa } \\
\text { Spesies } \\
\text { lumbuhan }\end{array}$ & $\begin{array}{l}\text { Terjadi } \\
\text { penurunan } \\
\text { pada jarak } \\
\text { pandang }\end{array}$ \\
\hline Tidak Sehat & $\begin{array}{l}\text { Peningkatan } \\
\text { Kardiovaskular } \\
\text { pada perokok } \\
\text { yang } \\
\text { sakit jantung }\end{array}$ & $\begin{array}{l}\text { Bau dan } \\
\text { kehilangan } \\
\text { warna, } \\
\text { peningkatan } \\
\text { reaktivitas } \\
\text { pembuluh } \\
\text { tenggorokan } \\
\text { pada penderita } \\
\text { asma }\end{array}$ & $\begin{array}{l}\text { Penurunan } \\
\text { kemampuan pada } \\
\text { atlet yangberlatih } \\
\text { keras }\end{array}$ & $\begin{array}{l}\text { Bau, } \\
\text { meningkatnya } \\
\text { Kerusakan } \\
\text { tanaman }\end{array}$ & $\begin{array}{l}\text { Jarak } \\
\text { pandang } \\
\text { turun dan } \\
\text { terjadi } \\
\text { pengotoran } \\
\text { debu di } \\
\text { manamana }\end{array}$ \\
\hline
\end{tabular}




\begin{tabular}{llllll}
\hline Sangat tidak & Meningkatnya & Meningkatnya & Olahraga ringan & Meningkatnya & Meningkatny \\
Sehat & kardiovaskular & sensitivitas & mangakibatkan & sensitivitas & a sensitivitas \\
& pada orang bukan & pasien yang & pengaruh & pada pasien & pada pasien \\
& perokok yang & berpenyaklt & parnafasan pada & berpenyakit & berpenyakit \\
& berpanyakit & asma dan & pasien yang & asthma dan & asthma dan \\
& jantung, dan akan & bronchitis & berpenyakit paru- & bronchitis & bronchitis \\
& tampak beberapa & & paru kronis & & \\
& kalemahan yang & & & & \\
& terlihat secara & & & & \\
Berbahaya & nyata & & & & \\
& Tingkat yang berbahaya bagi semua populasi yang terpapar & & \\
\end{tabular}

Sumber:

Keputusan Kepala Badan Pengendalian Dampak Lingkungan Tentang Pedoman Teknis Perhitungan dan Pelaporan Serta Informasi Indeks Standar Pencemar Udara (ISPU) nomor: KEP107/KABAPEDAL/11/1997 pasal 4.

\subsection{Protokol Zigbee}

Ergan menjelaskan pengertian protokol zigbee adalah protokol jaringan wireless dengan standar 802.15.4 memiliki keunggulan pengiriman data rate rendah, konsumsi daya rendah, dan biaya murah [4].

\subsection{Raspberry pi}

Raspberry pi merupakan sebuah komputer single board computer dikembangkan oleh yayasan raspberry pi dengan spesifikasi chip Broadcom BCM2835, prosesor ARM1176JZF-S 700 Mhz, VideoCore IV GPU, memory RAM 512 MB [5][6]. Raspberry Pi beroperasi seperti PC standar, membutuhkan keyboard untuk masuk perintah, unit display dan power supply. SD MIPRO merupakan kartu memori flash yang biasanya digunakan hard drive pada Raspberry Pi [7].

\section{Metode}

Pada penelitian ini terdiri dari tiga bagian utama yaitu perancangan prototype stasiun indeks standar pencemar udara (ISPU), perancangan akuisisi data secara nirkabel (wireless), dan pengujian sistem.

\section{Hasil}

Hasil yang didapatkan pada penelitian ini adalah berupa prototype sistem monitoring pencemaran gas karbon monoksida. Rincian perancangan sistem monitoring ISPU menggunakan protocol zigbee adalah sebagai berikut:

\subsection{Perancangan stasiun ISPU terdiri dari $\mathbf{4}$ tahapan yaitu:}

a) Pemasangan modul Xbee pada perangkat Arduino

Pada tahapan ini dilakukan pemasangan modul xbee pada perangkat arduino dengan menempatkan modul xbee pada socket xbee yang tersedia pada perangkat arduino. Pemasangan modul xbee pada perangkat arduino dapat dilihat pada Gambar 1.

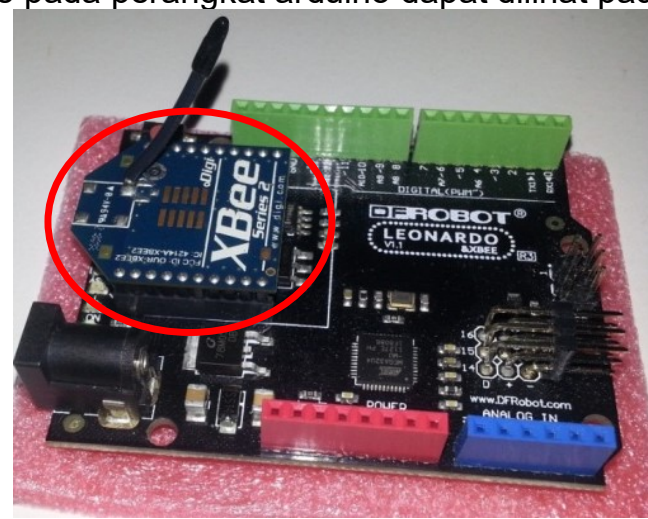

Gambar 1 Pemasangan modul xbee pada perangkat arduino

b) Pemasangan sensor CO 
Pada tahapan ini dilakukan pemasangan sensor $\mathrm{CO}$ pada pin arduino. Pin yang digunakan untuk menghubungkan sonsor $\mathrm{CO}$ dengan arduino adalah pin GND sebagai grounding, pin VCC $=5 \mathrm{~V}$ sebagai power, dan pin A0 sebagai masukkan data sensor.

c) Konfigurasi pengiriman data ISPU pada stasiun ISPU

Pada tahapan ini dilakukan penginstalan software IDE arduino dan X-CTU untuk mengatur konfigurasi stasiun ISPU. Software IDE arduino digunakan untuk menuliskan listing program arduino kemudian diupload ke dalam perangkat arduino. Software X-CTU digunakan untuk konfigurasi router dan koordinator modul xbee. Langkah selanjutnya untuk konfigurasi pengiriman data ISPU adala dengan mengatur kofigurasi default pada xbee. Selanjutnya pengaturan pada software X-CTU dengan PAN ID = 111, Channel Verification $=1$, Destination Address High $=0$, Destination Address Low $=0$ dan Baud Rate $=9600$. Tahap terakhir konfigurasi pengiriman data adalah melakukan penulisan listing program untuk pengiriman data sensor CO dapat dilihat pada Gambar 2.

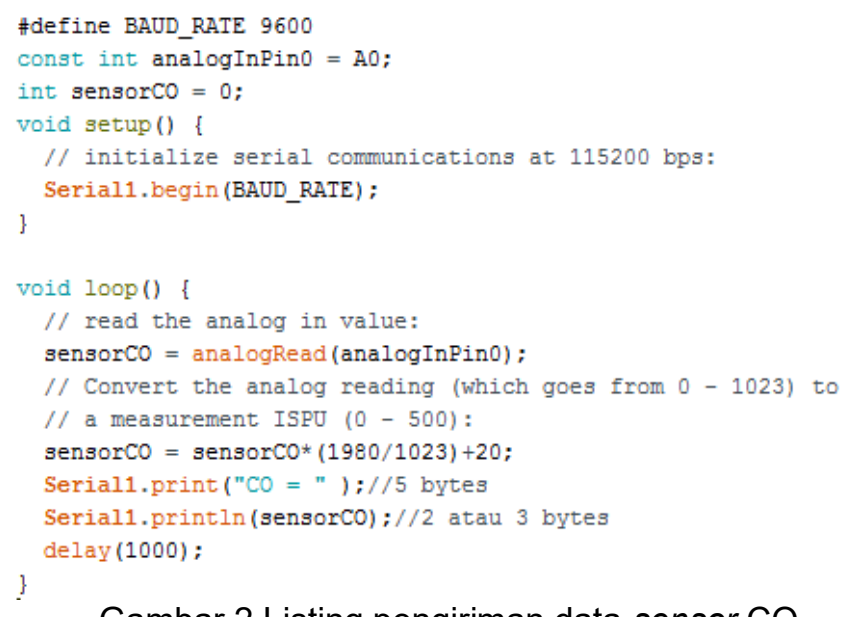

Gambar 2 Listing pengiriman data sensor CO

\subsection{Perancangan server akuisisi data ISPU dengan zigbee protocol}

Pada tahapan ini dilakukan perancangan server menggunakan perangkat raspberry pi dengan arduino dan xbee. Perancangan server akuisisi data ISPU dengan zigbee protocol terdiri dari beberapa tahapan yaitu:

a) Pemasangan perangkat arduino pada raspberry

Pada tahapan ini raspberry akan dihubungkan dengan arduino, untuk menghubungkannya yaitu dengan menggunakan kabel data USB to Data. Socket USB pada raspberry dihubungkan dengan socket data pada arduino. Pemasangan perangkat arduino pada raspberry dapat dilihat pada Gambar 3.

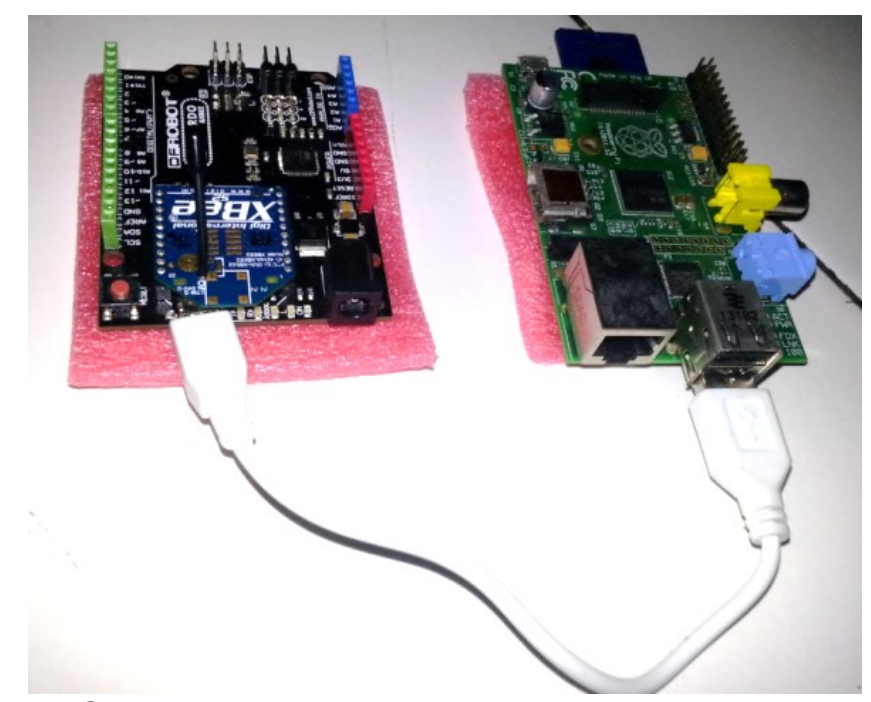

Gambar 3 Pemasangan arduino pada raspberry

b) Konfigurasi server penerima data sensor $\mathrm{CO}$ 
Pengaturan konfigurasi server penerima data data sensor $\mathrm{CO}$ dengan menggunakan software XCTU. Adapun pengaturan software X-CTU adalah sebagai berikut function set diubah menjadi zigbee coordinator AT, PAN ID = 111 dan Baud Rate $=9600$. Konfigurasi server penerima data dapat dilihat pada Gambar 4.

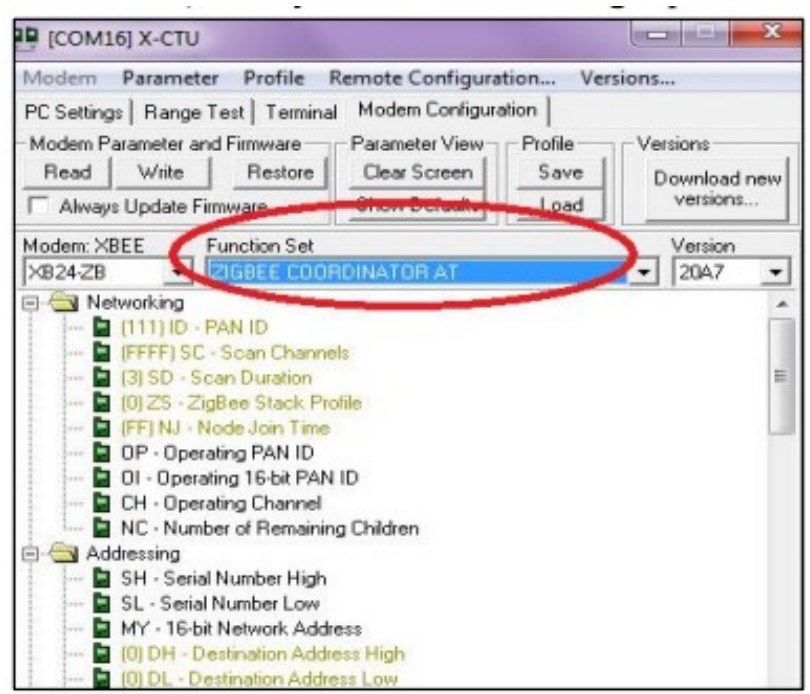

Gambar 4 Konfigurasi server penerima data data sensor CO

\subsection{Pengujian sistem}

Pada pengujian sistem telah berhasil menampilkan data hasil capture sensor CO pada layar monitor serial pada software arduino IDE. Hasil pengujian menjelaskan bahwa pengiriman data dari stasiun ISPU sensor CO ke server raspberry telah berhasil. Hasil pengujian ini ditampilkan pada Gambar 5.

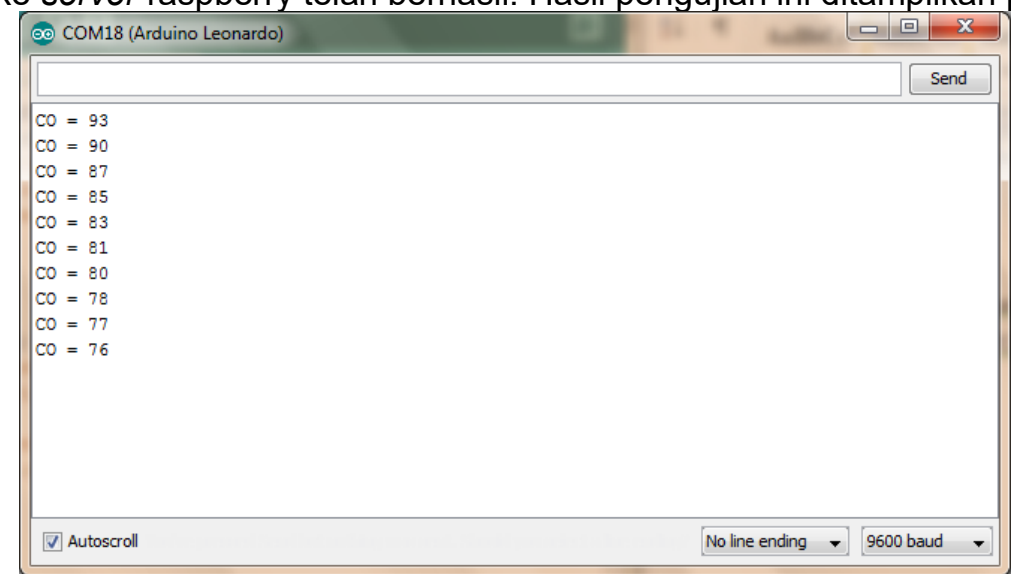

Gambar 5 Hasil pengujian pengiriman data sensor CO dari stasiun ISPU ke server raspberry

\section{Kesimpulan dan Saran}

\subsection{Kesimpulan}

Penelitian ini telah berhasil merancang sistem monitoring pencemaran udara gas CO dengan protokol zigbee. Penelitian yang telah dilakukan menghasilkan sebuah sistem yang secara realtime menampilkan data tingkat pencemaran udara gas karbon monoksida (CO) yang sangat berbahaya bagi kehidupan manusia. Sistem ini diharapkan membantu dalam pengontrolan wilayah sekitar kampus dari tingkat polusi udara gas CO. Pengontrolan ini dilakukan agar dapat dilakukan tindakan pencegahan pencemaran udara pada lingkungan tersebut.

\subsection{Saran}

Penelitian selanjutnya dapat dikembangkan dengan menambah jenis sensor gas lainnya dan melakukan perancangan interface berbasis web.

\section{Daftar Pustaka}


[1] Deputi Bidang Tata Lingkungan - Kementerian Negara Lingkungan Hidup. 2007. Memprakirakan Dampak Lingkungan Kualitas Udara.

[2] Badan Pengendalian Dampak Lingkungan. 1998. Pedoman Teknis Perhitungan dan Pelaporan Serta Informasi Indeks Standar Pencemar Udara (ISPU).

[3] Azis M. 2011. Rancang Bangun Sistem Akuisisi Data Berbasis WirelessSensor Network (WSN) dan Internet Access untuk Pengukuran Indeks Standar Pencemar Udara (ISPU) [tesis]. Bogor (ID): Institut Pertanian Bogor.

[4] Hastriyandi H. 2014. Pengembangan Sistem Pemantauan Suhu pada Greenhouse Berbasis Wireless Menggunakan Multi Sensor [tesis]. Bogor (ID): Institut Pertanian Bogor.

[5] Danymol R, Ajitha T, Gandhiraj R. 2013. Real-Time Communication System Design using RTLSDR and Raspberry Pi. International Conference on Advanced Computing and Communication Systems (ICACCS).

[6] Pereira V, Fernandes VA, Sequeira J. 2014. Low Cost Object Sorting Robotic Arm using Raspberry Pi. IEEE Global Humanitarian Technology Conference - South Asia Satellite (GHTCSAS).

[7] Vujovic' V, Maksimovic' M. 2014. Raspberry Pi as a Wireless Sensor Node: Performances and Constraints. MIPRO. 